\title{
Reflex Triggering Properties in Genetic Generalized and Focal Epilepsies by Questioning and Neuropsychological Electroencephalography Activation Methods
}

\author{
(D) Emel UR ÖZÇELIK, ${ }^{1,2}$ ๑) Dilek ATAKLI, ${ }^{2}$ ๑ Nermin GÖRKEM ŞiRINN, ${ }^{1}$

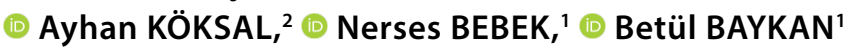 \\ 'Departments of Neurology and Clinical Neurophysiology, İstanbul University, İstanbul Faculty of Medicine, İstanbul, Turkey \\ ${ }^{2}$ Departments of Neurology, University of Health Sciences, Bakırköy Prof. Dr. Mazhar Osman Mental Health and Neurology \\ Training and Research Hospital, İstanbul, Turkey
}

\begin{abstract}
Summary
Objectives: Epileptogenesis is still not clearly understood. Therefore, there is an inevitable need for research that investigates triggers for reflex seizures and neuropsychological activation (NPA) methods using electroencephalography (EEG) in different epileptic syndromes. In this regard, we aimed to examine the characteristics and frequency of triggers for reflex seizures as well as changes in the frequency of epileptiform discharges (EDs), according to the stimulus in patients with generalized genetic epilepsy (GGE) and drug- resistant focal epilepsy (FE) by performing a comparative study with a survey and a neuropsychological EEG activation method, besides routine EEG.

Methods: A detailed and structured survey questioning seizure triggers was applied to patients with FE and GGE. Afterward, the changes in EDs in juvenile myoclonic epilepsy (JME), absence epilepsy (AE), and resistant FE groups were examined using NPA methods with EEG.

Results: The most frequently reported triggers in all patient groups $(n=66)$ were sleep deprivation $(68.2 \%)$, stress $(65.3 \%)$, fatigue/physical stress (53\%), awakening (42.4\%), and light stimuli (25.8\%). There was no significant difference between the JME ( $n=34), A E(n=16)$, and resistant $\mathrm{FE}(\mathrm{n}=16)$ groups in terms of either the triggering or inhibition of EDs in EEG by conventional activation and NPA methods. While the triggering of EDs occurred in $24 \%$ of patients by hyperventilation and in $18.1 \%$ of patients by intermittent photic stimulation, a similar triggering rate was detected in $21.2 \%$ of patients by NPA methods. In addition, while the results of the conventional EEG activation methods were negative, a triggered ED was observed in six patients during NPA (11\%). Only two patients showed an inhibition by the NPA methods. Four patients had EDs on their EEGs during the NPA methods associated with triggers reported in the questionnaire.

Conclusion: In $11 \%$ of patients, while an ED was not seen in conventional methods, we observed that ED triggering occurred with the NPA methods. Planning the NPA methods for specific triggers during EEG recordings by prior questioning on the seizure triggers of the patients and applying NPA as an additional triggering method, especially for patients who do not have EDs in EEG with standard activation methods, may be beneficial in terms of the correct diagnosis.
\end{abstract}

Keywords: Neuropsychological EEG activation methods; reflex epilepsy; survey.

Cite this article as: Ur Özçelik E, Ataklı D, Görkem Şirin N, Köksal A, Bebek N, Baykan B. Reflex Triggering Properties in Genetic Generalized and Focal Epilepsies by Questioning and Neuropsychological Electroencephalography Activation Methods. Epilepsi 2021;27:52-61.

\section{Giriş̧}

Refleks olarak tetiklenen nöbetler ve refleks epilepsiler çok uzun yıllardan beri bilinmekte ve altta yatan mekanizmala-

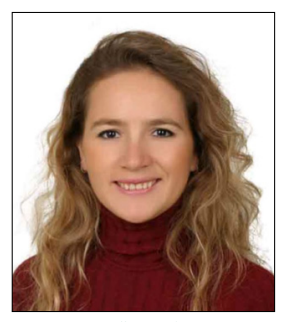

Corresponding author Emel UR ÖZÇELIK, M.D. e-mailemeluscas@gmail.com

Received 10.05.2020

Accepted 26.10.2020

Online date 24.01.2021

Content of this journal is licensed under a Creative Commons Attribution-NonCommercial 4.0 International License.

Dr. Emel UR ÖZÇELIK rın epileptogeneze ışık tutması açısından birçok araştırmacının dikkatini çekmektedir. Refleks nöbetler; spesifik bir dış uyaranla veya hastanın kendi aktivitesiyle uyarıldığı objektif ve tutarlı bir şekilde gösterilmiş olan nöbetlerdir. ${ }^{[1]}$ Tetikleyici faktörlere göre birçok refleks nöbet çeşidi tanımlanmıştır. ${ }^{[2]}$ Refleks nöbetlerin prevalansı ile ilgili kontrollü bir epidemiyolojik çalışma bulunmamaktadır. Epileptik hastalar arasında refleks nöbet görülme sıklığı ülkelere ve de merkezlere göre değişmekle birlikte ortalama \%5 civarındadır. ${ }^{[3]}$

Refleks nöbete neden olan uyaranları tetikleyiciler ve kolaylaştırıcılar olarak sınıflandırmanın daha doğru olduğu düşünülmektedir. ${ }^{[4]}$ En başta stres olmak üzere, uykusuzluk, uyku-uyanıklık geçişi, ateş, yorgunluk, aşırı egzersiz, alkol 


\section{Sorgulama ve Elektroensefalografide Nöropsikolojik Aktivasyon Yöntemleri ile Genetik Jeneralize ve Fokal Epilepsilerde Refleks Tetiklenme Özellikleri}

\section{Özet}

Amaç: Epileptogenezin halen aydınlatılamadığı düşünüldüğünde refleks tetikleyici uyaranları inceleyen, elektroensefalografide nöropsikolojik aktivasyon yöntemlerini farklı epilepsi sendromlarında irdeleyen araştırmalara gerek vardır. Bu çalışmada, genetik jeneralize epilepsi ve dirençli fokal epilepsi tanısı olan olgularda standart elektroensefalografi ile birlikte nöropsikolojik elektroensefalografi aktivasyon yöntemlerini uygulayarak epileptiform deşarj sıklığının uyarana göre değişiminin incelenmesi, refleks nöbet tetiklenme özellikleri ile sıklığının anket ve elektroensefalografi aracılığı ile karşılaştırmalı olarak araştırıması amaçlanmıştır.

Gereç ve Yöntem: Genetik jeneralize epilepsi ve fokal epilepsi tanılı hastalara nöbet tetikleyicilerini sorgulayan ayrıntılı ve standardize bir anket uygulanmıştır. Anketler yüz yüze ve az sayıda hastada özel durumlarda telefonla yapılmıştır. Ardından jüvenil miyoklonik epilepsi, absans epilepsi ve dirençli fokal epilepsi gruplarında nöropsikolojik aktivasyon yöntemleriyle elektroensefalografide epileptiform deşarjların değişimi incelenmiştir.

Bulgular: Tüm hasta grubunda ( $n=66)$ en sık bildirilen tetikleyiciler; uykusuzluk (\%68.2), stres (\%65.3), yorgunluk/fiziksel stres (\%53), uykudan uyanma (\%42.4) ve ışık uyaran (\%25.8) olmuştur. Jüvenil miyoklonik epilepsi $(n=34)$, absans epilepsi $(n=16)$ ve dirençli fokal epilepsi $(n=16)$ grupları arasında, standart aktivasyon ve nöropsikolojik aktivasyon yöntemleri ile elektroensefalografide görülen epileptiform deşarjların provoke olmaları açısından anlamlı bir fark saptanmamıştır. Hiperventilasyon ile hastaların \%24'ünde, intermittant fotik stimülasyon ile \%18.1'inde, nöropsikolojik aktivasyon ile \%21.2'sinde epileptiform deşarjlarda provokasyon izlenmiştir. Standart aktivasyon yöntemlerinde epileptiform deşarj izlenmediği halde, nöropsikolojik aktivasyon ile epileptiform deşarjların provokasyonu 6 (\%11) hastada görülmüştür. Sadece iki hastada nöropsikolojik aktivasyon ile inhibisyon izlenmiştir. Dört hastanın anketlerinde bildirdikleri tetikleyicileri ile ilişkili nöropsikolojik aktivasyon yöntemleri sırasında elektroensefalografilerde epileptiform deşarj izlenmiştir.

Sonuç: Çalışmada, hastaların \%11'inde konvansiyonel yöntemlerde epileptiform deşarj izlenmezken, nöropsikolojik aktivasyon yöntemleri ile epileptiform deşarj provokasyonu geliştiği saptanmıştır. Nöbet tetikleyicilerinin sorgulanarak elektroensefalografi kayıtları sırasında spesifik tetikleyicilere yönelik nöropsikolojik aktivasyon yöntemlerinin planlanmasının ve özellikle elektroensefalografilerde standart aktivasyon yöntemleri ile epileptiform deşarj görülmeyen hastalarda nöropsikolojik aktivasyonun ek provokasyon yöntemi olarak uygulanmasının tanı açısından fayda sağlayabileceği kanısındayız.

Anahtar sözcükler: Nöropsikolojik aktivasyon yöntemleri; refleks epilepsi; anket.

yoksunluğu, doz atlama ve menstrüel dönemler kolaylaştırıcı faktörler olsalar da hastalar tarafından sıklıkla tetikleyici olarak bildirilmektedir. ${ }^{[5]}$ Özellikle mezial temporal lob epilepsili (MTLE) hastalar üzüntü, kaygı, kızgınlık, gerginlik ve stresi tetikleyiciler arasında sık rapor etmişlerdir. ${ }^{[6]}$ Refleks nöbetlerin gelişmesinde kompleks genetik ve çevresel faktörler rol almaktadır. ${ }^{[7]}$ Genel görüş; tetikleyici (ışık, praksi gibi) ya da kolaylaştırıcı (ateş, alkol gibi) faktörlerin genetik ve çevresel etkiler sonucu gelişen serebral hipereksitabl alanların nöbet eşiklerini etkiledikleri yönündedir. ${ }^{[8]}$ Refleks epileptik mekanizmaların varlığının genetik jeneralize epilepsilerde (GJE), fokal epilepsilere (FE) göre daha sık olduğu düşünülmektedir. ${ }^{[9]}$ Sıklıkla GJE'lilerde gördüğümüz jeneralize refleks nöbetleri, yanıp sönen parlak ışıklar, görsel paternler, hızlı göz kırpma gibi görsel uyaranlar ile düşünme, praksi ve dilsel işlevlerin tetiklediği bildirilmiştir. FE'lilerdeki refleks nöbetleri ise propriyoseptif ve somatosensöriyel uyaranlar (ani hareket, ani kuvvetli bir vuruş, belli bir vücut bölgesine taktil veya termal uyarı) ile müzik dinleme, yemek yeme, okuma, sıcak su, orgazm gibi uyaranların tetiklediği bildirilmiştir. ${ }^{[7]}$

Nadir refleks mekanizmaları ve bunların elektroensefalografideki (EEG) etkisini objektif olarak ortaya çıkarmak için Mat- suoka ve ark., ${ }^{[10]}$ sesli ve sessiz okuma, konuşma, mental hesaplama, yazarak hesaplama, yazma, uzaysal yapılandırmayı da içine alan yaklaşık 20 dakika süren EEG'de nöropsikolojik aktivasyon (NPA) yöntemini geliştirmişlerdir. İzleyen yıllarda birkaç değişik merkezde başka araştırıcılar da bu protokolü aynen ya da modifikasyonlarla uygulayarak farklı kognitif işlevlerin epileptiform deşarjları (ED) inhibe veya provoke edebildiğini ve görülme oranlarını bildirmişlerdir. ${ }^{[11,12]}$

Standart bir EEG kayıtlaması sırasında intermittant fotik stimülasyon (IFS) vererek fotosensitivite olup olmadığı değerlendirilebilirken, hastanın emosyonel durumunun ve yüksek mental işlevlerinin ED'leri tetiklemesine yönelik aktivasyon yöntemleri rutin uygulamada kullanılmamaktadır; ancak bildirilen nöbet tetikleyici faktörler gözönüne alındığında bazı hastalarda yararı olabileceği düşünülebilir.

Tüm bu nedenlerle epileptogenezin hâlen aydınlatılamadığı da düşünüldüğünde refleks tetikleyici uyaranları inceleyen ve EEG'de NPA yöntemlerini farklı epilepsi sendromlarında irdeleyen araştırmalara gerek vardır. Bu çalışmada, GJE'si ve dirençli FE'si olan olgularda standart EEG ile birlikte nöropsikolojik EEG aktivasyon yöntemlerini uygulayarak ED sıklığının uyarana göre değişiminin incelenmesi, refleks nöbet 
tetiklenme özellikleri ile sıklığının anket ve EEG aracılığıyla araştırılması amaçlanmıştır.

\section{Gereç ve Yöntem}

Çalışma için Etik Kurul onayı ile tüm katılımcılardan yazılı ve sözlü olarak Helsinki bildirgesine göre gönüllü onam formu alındı.

Çalışmaya dahil edilen hastalar, 2016-2019 yılları arasında iki özelleşmiş epilepsi polikliniğinden (video-EEG kayıtlaması için yönlendirilmiş olan) en az bir yıldır takip edilmekte olan, "International League Against Epilepsy (ILAE) 2017 kriterlerine göre kesin jüvenil miyoklonik epilepsi (JME), absans epilepsi (AE) ve FE tanısı almış olan 15-65 yaş arasındaki hastaların içinden ardışık olarak seçildi. ${ }^{[13]}$

Rutin kontrolleri sırasında FE veya GJE tanısı olan hastalara nöbet tetikleyici durumlarını sorgulayan ayrıntılı ve standardize bir anket uygulandı (Ek 1). Anketler katılımcılar ile yüz yüze ve az sayıda hastada bazı özel durumlarda telefonla aynı araştırmacı tarafından yapıldı. Anket sonuçlarına göre en az bir tetikleyici faktörü tutarlı şekilde bildiren JME'li 34 hasta ile kontrol grubu olarak 18 AE'li ve dirençli FE'si olan 20 hasta NPA'lı EEG protokolü uygulanmak üzere çalışmaya alındı. Dirençli FE'li hastalar MTLE veya nedeni bilinmeyen fokal epilepsili (NBFE) hastalar arasından seçildi. AE'li iki hasta ve FE'li dört hasta; dört hasta anket sorularını cevaplamadığı için, iki hastada semptomatik etiyoloji saptandığı için çalışmadan dışlandı. Toplam 66 hastanın NPA'lı EEG sonuçları analiz edildi. Kontrol grubuna dahil edilen dirençli FE'si olanlar, çalışma sürecinde video-EEG monitörizasyonu ile EEG kaydı yapılan, ILAE 2017 tanı kriterlerine göre FE tanısı almış ve dirençli hastalar arasından seçildi. ${ }^{[14]}$ Dışlama kriterleri oluşturuldu (Tablo 1); bu kriterlere uyan hastalar çalışmaya dahil edilmedi. Kwan ve ark.'na ${ }^{[14]}$ göre

Tablo 1. Dışlama kriterleri

- 15 yaştan küçük, 65 yaştan büyük olma

- Epilepsi sendrom tanısında kuşku olması ve öyküde $J M E, A E$ ve dirençli FE için tipik klinik ve/veya EEG bulgularının olmaması

- NPA uygulanmasına engel teşkil edecek aşağıdaki özelliklerin olması:

*Demansı olan olgular

*Ciddi psikiyatrik hastalığı olanlar

*Mental geriliği olanlar

*Okuma-yazma ve Türkçe bilmeyenler

*Onam formunu imzalamayanlar

JME: Jüvenil miyoklonik epilepsi; AE: Absans epilepsi; FE: Fokal epilepsi; EEG: Elektroensefalografi; NPA: Nöropsikolojik aktivasyon. hastaların tedavi yanıtları ve dirençli epilepsi varlığı değerlendirilmiş olup, prognozları iyi, orta ve kötü düzeyde olarak derecelendirildi.

EEG kayıt protokolü- Video-EEG kayıtlaması için Matsuoka ve ark.nın ${ }^{[10]}$ uyguladığı NPA yöntemi modifiye edilerek bir protokol oluşturuldu (Tablo 2).

Uluslararası 10-20 elektrot yerleşim sistemine göre konumlandırılan elektrotlarla saçlı deriden video-EEG kaydı 32 kanallı dijital cihaz (Medelec) ile yapıldı. Bütün kayıtlar hastalar uykularını iyi almış ve tok olarak günün aynı saatlerinde (11:30-13:30) yapıldı. Son 48 saat içinde nöbet geçirmiş olanlara kayıt yapılmayarak ertelendi. Hastalara sakin, sessiz bir ortamda, sandalyede oturmuş olarak 1 saat 20 dakika boyunca Tablo 2'de özetlenen NPA'lı EEG kaydı, deneyimli bir EEG teknisyeni tarafından ve araştırmacının gözetiminde uygulandı.

Tablo 2. Nöropsikolojik aktivasyon yöntemlerini içeren video-EEG protokolü

1. Gözler kapalı bazal kayıt-15 dakika +7 kez göz açmagöz kapama

2. Hiperventilasyon (HV) -5 dakika

3. Gözler açık kayıt-5 dakika (3 dakika post-HV dönemi, sonraki 2 dakika post-HV sonrası dinlenme)

4. İntermittant fotik stimülasyon-5 saniye göz açık, 5 saniye göz kapalı, 5 saniye ara verilerek $(1,2,8,10,15$, $18,20,25,30,40 \mathrm{~Hz}$ - frekanslarında)

$$
-2 \text { dakika ara- }
$$

5. Kognitif testler

- Her biri 3 dakika boyunca uygulandı

- Her test arasında dinlenme dönemi olarak 2 dakika aktivasyonsuz kayda devam edildi

Okuma: Anadilinde orta zorlukta bir metni testin başında ve İngilizce başka bir metni testin sonunda yüksek sesle okuma

Dikkat: Harflerin rastgele yazıldığı bir kâğıtta A, I, B ve W harflerini sırasıyla işaretleme

Praksi: Rubik kübün bir tarafını aynı renk yapmaya çalışma Yazma*: Nöbetlerine dair duygu ve düşüncelerini yazma Mental hesaplama: Matematiksel işlemleri zihinsel olarak yapma

Kopyalama*: Rey-Osterrieth kompleks figürünün kopyalanması

Konuşma: Nöbetleriyle ilgili hisleri ve nasıl nöbet geçirdikleri hakkında

Yazarak hesaplama*: Matematiksel işlemleri basitten zora doğru kalemle yapma

*Bu testler aynı zamanda praksi değerlendirmesi için de kullanılmıştır. 
EEG'nin yorumlanması- Deneyimli klinik nörofizyologlar tarafından standart bir forma göre aynı anda tüm ED'ler ilgili bölümlere göre sayılarak EEG'ler okundu. Okumalar başlamadan önce 1971 Maulsby'nin modifiye edilmiş kriterlerine göre okuma uzlaşımı oluşturuldu. ${ }^{[15]}$ Keskin dalga, diken dalga, çoklu diken dalga, diken yavaş ve keskin yavaş dalga kompleksleri ED olarak sayıldı. Deşarjların izole veya gruplar halinde olması durumunda her bir ED ayrı ayrı sayıldı. Bazal kayıt, her bir aktivasyon ve aktivasyon sonrası dinlenme sırasındaki kayıtlar için ED sayıları not edildi.

Verilerin analizi- Anket ve EEG incelemeleri yapılan epilepsi hastalarının ayrıntılı verileri (yaş, cinsiyet, sendrom tipi, ilaç kullanımı, görüntüleme özellikleri, anket sonuçları, bazal kayıt ve her bir aktivasyon sırasındaki ED sayıları) "Statistical Program for Social Sciences (SPSS)" 21 dijital veri tabanında toplanarak istatistiksel analizleri yapıldı. Nicel verilerin dağılımının normalliği için Shapiro-Wilk normallik testi kullanıldı; normal dağılıyorsa bağımsız örneklem t-testi ya da normal dağılmıyorsa Mann-Whitney U testi kullanılarak karşılaştırıldı. Üç grup (JME, AE, FE) arasında yaş, nöbet başlangıç yaşı, nöbet sürelerinin gruplar arasında karşılaştırılması için parametrik olmayan testlerden olan Kruskal Wallis seçildi; anlamlı çıkan sonuçlar Bonferroni düzeltmesi dikkate alınarak $(p=0.05 / 3=0.017)$ posthoc analizler ile incelendi. Gruplar arası cinsiyet karşılaştırmaları ve tetikleyicilerin sorgulandığı anket sorularına verilen "provokasyon/ inhibisyon/etkisi yok/ilgisiz" yanıtlarının kıyaslamaları gibi diğer kategorik değişkenlerin karşılaştırılması için Pearson ki-kare testi ya da Fisher'in Exact testi seçilerek uygulandı. İstatistiksel anlamlılık sınırı $\mathrm{p}<0.05$ olarak kabul edildi.

\section{- Diken/keskin dalga aktivitelerinin sayılması}

Okuyucular arasındaki uyumu araştırmak için önce rastgele seçilmiş beşer dakikalık 10 bölüm için tanımlanmış kriterlere göre diken/keskin dalgalar sayılarak araştırıcılar arasındaki tutarlılık kappa (к) analizi ile değerlendirildi. (к) faktörü araştırıcılar arasındaki güvenilirliği değerlendirirken şans faktörünü elimine etmek üzere geliştirilmiş bir istatistiksel yöntemdir. (к) faktörü; 0-0.20 ise az, 0.21-0.40 ise zayıf, 0.410.60 ise orta, $0.61-0.80$ ise iyi, $0.81-1.00$ ise mükemmel tutarlılık olarak değerlendirilmektedir.

Bazal EEG aktivitesi (15 dakika) üçer dakikalık beş bölüme ayrıldı ve bu her bir bölüm için ayrı ayrı diken/keskin dalga aktiviteleri sayıldı. Hiperventilasyon (HV) (5 dakika), postHV (3 dakika), IFS (4 dakika), göz açma-göz kapama (GAGK) (5 dakika) sırasında ortaya çıkan diken/keskin dalga aktiviteleri sayıldı. Kognitif testlerin her birinin sırasında (3 dakika) ve test aralarındaki dinlenme sürelerindeki (2 dakika) diken/ keskin dalga aktiviteleri sayıldı.
- Ortalama ED sayısının, standart sapma (standard deviation; SS) ve güven aralığının (confidence interval; $\mathrm{CI}$ ) hesaplanması ve değerlendirilmesi

1) Her hastanın bazal EEG kaydındaki üçer dakikadan oluşan her bir bölümdeki ED'lerin dakikadaki ortalama sayıları hesaplandı (ED sayısı/3 dakika). Ardından bu beş bölümün ortalama değerleri toplanarak beşe bölündü ve tüm bazal kayıt için ortalama diken sayısı belirlendi (tüm bazal ED sayısı/15 dakika).

2) Konvansiyonel aktivasyon yöntemleri ile NPA yöntemlerinin süreleri farklı olduğu için; her aktivasyonun süresi boyunca izlenen diken/keskin sayısı o aktivasyonun toplam süresine bölünerek dakikadaki ortalama ED sayısı hesaplandı (ED sayısı/toplam süre) (örn. okuma aktivasyonu için: diken sayısı/5 dakika; IFS aktivasyonu için: diken sayısı/4 dakika gibi).

Hiperventilasyon ve kognitif testler için aktivasyonların hemen bitiminden sonra da EEG üzerindeki etkilerinin devam edebileceği düşünüldü; dakikadaki ortalama ED hesaplanırken aktivasyon sırasındaki ve hemen sonrasındaki dinlenme sürelerinin toplamı dikkate alındı.

3) Bazal EEG aktivitesinde görülen ED'lerin SS değerleri, bazal kayıttaki üçer dakikalık beş ayrı bölümün ortalama diken sayıları üzerinden hesaplandı (Bazal kayıt ve aktivasyonlar sırasındaki dakikadaki ortalama ED sayıları, bazal kaydın SS ve $\mathrm{Cl}$ değerleri her hasta için ayrı ayrı hesaplandı).

4) Aktivasyonlar ile ED'lerin provoke/inhibe olup olmadığına bazaldeki ortalama ED sayısının \%95 Cl değerine göre karar verildi. Aktivasyonlar sırasındaki ED'lerin ortalaması $>\% 95 \mathrm{Cl}$ üst limiti ise aktivasyon provokatif, ED'lerin ortalaması <\%95 Cl alt limiti ise inhibitör ve bu alt ve üst limit arasındaysa da etkisiz olarak değerlendirildi.

\section{Bulgular}

Anket ve NPA'lı EEG kaydı, JME'si (\%51.5), AE'si (\%24.2) ve dirençli FE'si (\%24.2) olan 39'u kadın olmak üzere toplam 66 hastaya yapılmıştır. JME grubundaki 34 hastanın 8'ini (\%23.5) çocukluk çağı absans epilepsisinden (ÇÇAE) JME'ye dönüşenler oluşturmaktaydı. FE grubundaki 16 hastanın 8'i (\%50) MTLE, 8'i ise NBFE'lilerden oluşmaktaydı. AE grubunda ise 2 (\%12.5) hasta göz kapağı miyoklonili absans epilepsi (GKMAE), 5 (\%31.2) hasta ÇÇAE, 9 (\%56.2) hasta ise jüvenil absans epilepsi (JAE) idi. JME grubundaki 18 (\%52.9) hasta, AE grubunda ise 10 (\%62.5) hasta fotosensitif (FS) idi.

Demografik ve klinik özellikleri incelendiğinde; $A E$ ve JME grupları arasında yaş ortalamaları, nöbet başlangıç yaşları 
ve hastalık süreleri açııından anlamlı fark saptanmamıştır. AE ve FE grupları arasında da yaş ortalamaları, nöbet başlangıç yaşları ve hastalık süreleri açısından anlamlı fark yoktu. JME ve FE grupları arasında ise hastaların yaş ortalamaları açııından anlamlı fark saptanırken $(p=0.008)$; nöbet başlangıç yaşları ve hastalık süreleri açısından anlamlı fark saptanmamıştır. Hastaların demografik verileri Tablo 3'te özetlenmiştir.

Hastaların \%57.6'sı monoterapi, geri kalan hastalar politerapi almaktaydı. FE grubunun \%93.3'ü politerapi alıyorken, AE'lilerin \%31.3'ü, JME'lilerin ise \%23.5'i politerapi alıyordu. İki hasta herhangi bir antiepileptik almıyordu. EEG kaydı yapılan tüm hastalar arasında valproik asit (\%45.5) ve levetirasetam (\%45.5) kullanımı yaygın olup, lamotrijin (\%19.7), karbamazepin (\%18.2), lakozamid (\%12.1), topiramat (\%10.6) ve pregabalin (\%4.5) bunu takip etmekteydi. En yüksek oranda valproik asit kullanımı JME grubunda (\%61.8) iken; en yüksek oranda karbamazepin kullanımı FE grubundaydı (\%91.7). Dirençli FE grubundaki hastaların hepsinin nöbet kontrol düzeyleri kötü iken, JME'lilerin \%17.6'sının, AE'lilerin ise \%12.5'inin nöbet kontrol düzeyleri kötü idi.

Anket sonuçları- Ankette, hastaların \%77.3'ü $(n=51)$ bazen, \%6.1'i $(n=4)$ sıklıkla nöbetlerinin belli uyarılarla tetiklendiğini söylerken; \%16.7 ( $n=11)$ 'si ataklarının asla belli uyarılarla tetiklenmediğini bildirmişlerdir. Hastaların sadece 3 (\%4.5)'ü bazen nöbetlerine engel olabildiklerini söylemişlerdir. Gruplar arasında anlamlı fark bulunmamıştır. En sık bildirilen tetikleyiciler; uykusuzluk (\%68.2), stres (\%65.3), yorgunluk/fiziksel stres (\%53), uykudan uyanma (\%42.4) ve ışık uyaran (\%25.8) olmuştur. Işık uyaranla tetiklenme JME ve AE grubunda benzer oranlarda, FE grubunda ise hiç bildirilmemiştir. Uykusuzlukla nöbet geçirme JME'lilerin \%97.1'inde bildirilmişken, AE'lilerin \%50'sinde, FE'lilerin ise $\% 25^{\prime}$ inde bildirilmiştir ( $p=0.001$ ). Yine uykudan uyanma ile nöbet geçirenlerin \%92.9'u JME grubunda iken, AE grubunda iki hasta tarafından bildirilmiş; FE grubunda ise hiç bildirilmemiştir $(p=0.001)$. Stresle nöbet geçirme oranları gruplar arasında oldukça benzer bulunmuştur. Yorgunlukla nöbet geçirme sıklığı JME (\%58.8) ve AE (\%56.3) gruplarında benzer, FE grubunda ise $\% 37.5$ tespit edilmiştir.

Her üç grup arasında anlamlı fark olmayan diğer uyaranlar; düşünmek, konsantre olmak, farklı şeyler arasında karar vermeye çalışmak, zihinsel ve yazarak hesap yapmak gibi bilişsel olarak zorlanılan durumlar; alkol almak, kahve içmek, bazı hoş kokular/tatlar ve hoş olmayan tatlar/kokular; tamirat, elişi gibi komplike hareketler; özel ya da duygusal konuşmalar; emosyonel stres, açlık, oruç tutmak ve menstrüasyon idi. Bilgisayarda çalışma/oyun oynama ile tetiklenme FE grubunda hiç bildirilmemişken; JME grubunda dört, $A E$ grubunda ise iki kişi tarafından bildirilmiştir. Desenlerle tetiklenme AE grubunda bir, JME grubunda bir kişi tarafından bildirilmiştir. Sorgulanan diğer uyaranların ise her üç grupta hiç nöbet tetikleyici etkilerinin olmadığı görülmüştür.

Nöropsikolojik aktivasyonlu EEG sonuçları- Aynı klinikte yetişmiş, deneyimli, klinik nörofizyoloji uzmanı EEG okuyucuları arasındaki uyumu gösteren $(\mathrm{k})$ faktörü $=0.6$ (iyi) idi.

Hastaların \%56 ( $\mathrm{n}=37 ; 22 \mathrm{JME}, 8 \mathrm{AE}, 7 \mathrm{FE}$ )'sında bazal EEG kaydında ED görülmemiştir. Bazal EEG'sinde ED görülenlerin toplam oranı \%43.9 $(n=29)$ tespit edilmiştir. JME'lilerin \%35'inde $(n=12)$, AE'lilerin \%50'sinde $(n=8)$, dirençli FE grubunun ise \%56.3'ünün ( $n=9)$ bazal EEG'lerinde ED izlenmiştir. $A E$, JME ve FE grupları bazal EEG'lerinde ED olup olmamasına göre karşılaştııılıklarında aralarında anlamlı fark saptanmamıştır $(p=0.324)$. Deşarjların inhibisyonu bazal EEG'de deşarjları görülen hastalar üzerinden değerlendirilebilirken, provokatif etkiler için bazalde ED yoksa da değerlendirme yapılmıştır. Kayıtlar sırasında JME'li bir hasta HV ve Rubik küp aktivasyonlarının hemen sonrasında, diğer bir JME'li hasta bazal EEG kaydı ve HV sırasında, AE'li bir hasta ise HV sırasında kısa süreli absans nöbeti

Tablo 3. Nöropsikolojik aktivasyonlu elektroensefalografi yapılan hastaların demografik verileri

\begin{tabular}{lcccc}
\hline & $\mathrm{JME}(\mathrm{n}=34)$ & $\mathrm{AE}(\mathrm{n}=16)$ & $\mathrm{FE}(\mathrm{n}=16)$ & $\mathrm{p}$ \\
& Ortalama $\pm S S$ (aralık) & Ortalama \pm SS (aralık) & Ortalama \pm SS (aralık) & \\
\hline Yaş ortalaması & $27.74 \pm 6.954$ & $32.9 \pm 12.086$ & $35.38 \pm 10.151$ & $0.022^{\mathrm{a}}$ \\
& $(16-46)$ & $(19-65)$ & $(18-55)$ & \\
Cinsiyet (kadın/erkek) & $19 / 14$ & $13 / 3$ & $6 / 10$ & $0.420^{\mathrm{b}}$ \\
Nöbet başlangıc yaşı & $14.15 \pm 4.473$ & $12.31 \pm 4.909$ & $16.47 \pm 10.914$ & \\
& $(6-26)$ & $(4-21)$ & $(3-35)$ & $0.596^{\mathrm{a}}$ \\
Hastalık süresi & $12.94 \pm 7.888$ & $20.38 \pm 11.938$ & $18.20 \pm 13.375$ & $0.056^{\mathrm{a}}$ \\
\hline
\end{tabular}

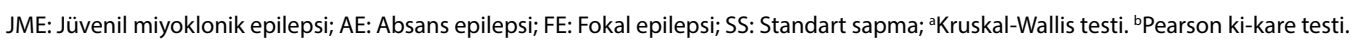


Tablo 4. Nöropsikolojik aktivasyonlu EEG yöntemlerinin ve konvansiyonel yöntemlerin etkilediği hasta sayısı

\begin{tabular}{llc}
\hline & Etki & $\begin{array}{c}\% 95 \text { Cl'ya göre (\%), } \\
\text { kişi sayısı }\end{array}$ \\
\hline HV & Provokatif & $\% 24(n=16)$ \\
IFS & İnhibitör & $\% 0$ \\
NPA (konv+/-) & Provokatif & $\% 18.1(n=12)$ \\
& İnhibitör & $\% 0$ \\
NPA (konv-) & İnhibitör* & $\% 21.2(n=14)$ \\
\hline
\end{tabular}

EEG: Elektroensefalografi; HV: Hiperventilasyon; IFS: İntermittant fotik stimülasyon; NPA (konv-): Konvansiyonel yöntemlerde provokasyon olmaksızın sadece nöropsikolojik aktivasyon ile, NPA (konv+/-): Konvansiyonel yöntemlerle ve/veya nöropsikolojik aktivasyon ile. *: Sadece bazal EEG'de deşarjı olan 26 hasta arasında değerlendirilebildi.

geçirmiştir. Nöbet geçiren hastalar da NPA yöntemlerinin inhibitör etkisi açısından değerlendirme dışı bırakıldığı için toplam 26 hastada inhibisyon olasılığı değerlendirilebilmiştir

Tüm hastalarda konvansiyonel yöntemlerle ED'lerin provokasyonu HV ile \%24 ( $n=16)$, IFS ile \%18.1 oranında izlenmiş; gruplar arasında istatistiksel olarak anlamlı fark bulunmamıştır ( $p=0.708$ ). NPA yöntemleri ile hastaların \%21.2'sinde ( $n=14 ; 6 \mathrm{JME}, 3 \mathrm{AE}, 5 \mathrm{FE}$ ) provokatif etki izlenirken, \%78.8'inde $(n=52)$ provokatif etki izlenmemiştir. Konvansiyonel yöntemlerin ED'leri provoke etmeyip, sadece NPA yöntemleri ile ED'lerinde provokasyon görülenlerin sayısının 6 (2 JME, $4 \mathrm{FE}$ ) kişi olduğu belirlenmiş (\%11) ve bu olguların 3 (2 FE, $1 \mathrm{JME}$ )'ünde bazal kayıtlarında hiç ED yokken, NPA yöntem- leri ile ED'ler tetiklenmiştir. Sadece 2 (1 JME, $1 \mathrm{FE}$ ) hastada NPA yöntemleri ile inhibisyon izlenmiştir (Tablo 4). JME, AE ve FE grupları arasında konvansiyonel ve NPA yöntemleri ile ED'lerin provoke olması açısından istatistiksel olarak anlamlı fark saptanmamıştır (sırasıyla $\mathrm{p}=0.507 ; \mathrm{p}=0.167$ ).

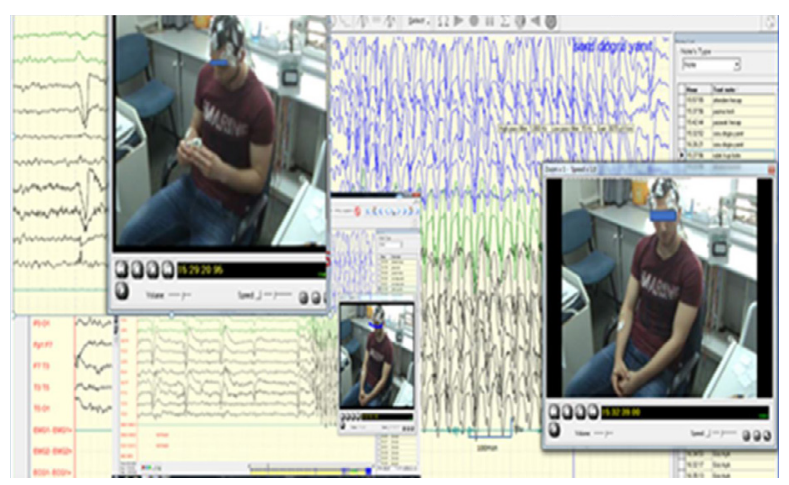

Şekil 2. Praksi ile provokasyonun görüldüğü elektroensefalografi örneği (21 y/E. Rubik küp çevirme sonrasında absans nöbeti izlenen jüvenil miyoklonik epilepsili hasta.).

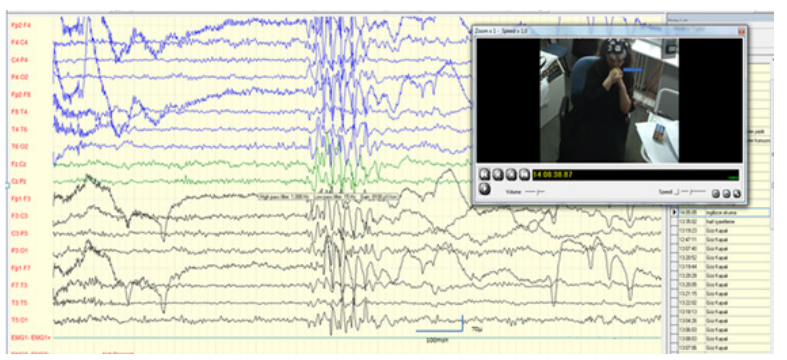

Şekil 3. Okuma ile provokasyonun görüldüğü elektroensefalografi örneği (21 y/K. İngilizce okumanın sonrasında epileptiform deşarj sayısında artış görülen jüvenil miyoklonik epilepsili hasta.).

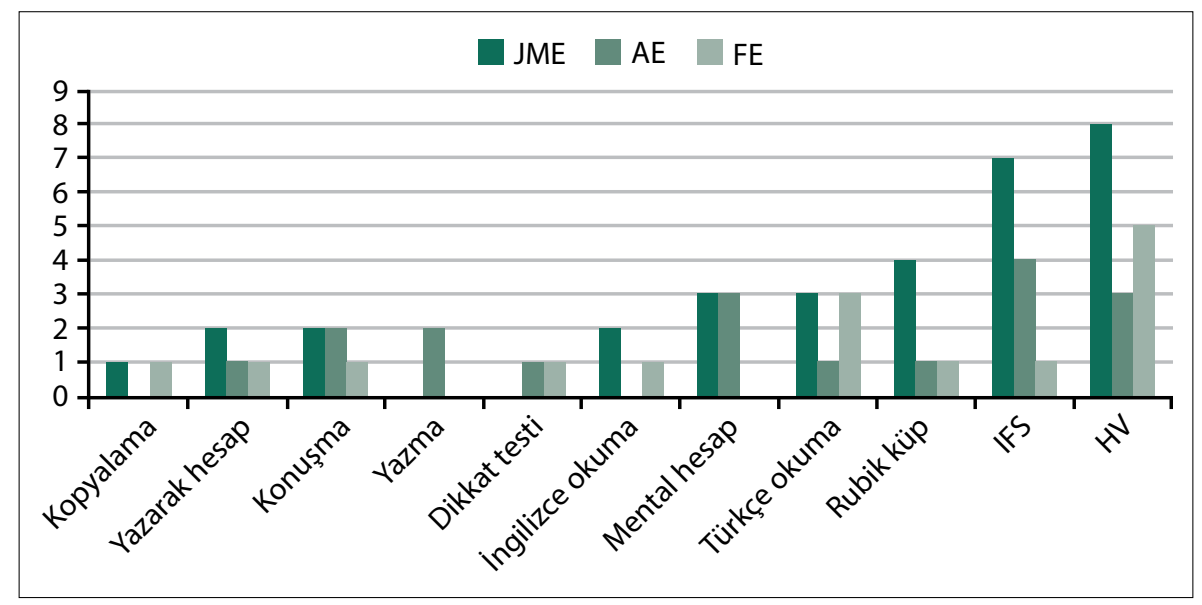

Şekil 1. Konvansiyonel ve nöropsikolojik aktivasyon yöntemleri ile EEG'de provokasyon görülen hasta sayısı (EEG: Elektroensefalografi, İFS: İntermittant fotik stimülasyon, HV: Hiperventilasyon). 
Tablo 5. Nöropsikolojik aktivasyon yöntemleriyle EEG'de provokasyon/inhibisyon görülen hastalar

\begin{tabular}{|c|c|c|c|c|}
\hline Yaş/Cinsiyet & Sendrom & Prognoz & Anket cevabı & NPA-EEG \\
\hline $20 y, E$ & JME-NFS & iyi & & HV + NPA provokasyon (Rubik küp) \\
\hline $22 y, K$ & JME-FS & iyi & Düşünmek* & $\begin{array}{l}\text { HV + IFS + NPA provokasyon } \\
\text { (Türkçe okuma, Mental hesaplama, Rubik küp) }\end{array}$ \\
\hline $26 y, K$ & JME-NFS & orta & & $\begin{array}{l}\text { NPA ile inhibisyon } \\
\text { (Yazarak hesaplama, Mental hesaplama, Dikkat testi, } \\
\text { Rubik küp, Türkçe okuma) }\end{array}$ \\
\hline $28 y, E$ & JME-FS & orta & & IFS+NPA provokasyon (Konuşma, Mental hesaplama) \\
\hline $36 y, K$ & JME-FS & iyi & & IFS+NPA ile provokasyon (Rubik küp) \\
\hline $21 \mathrm{y}, \mathrm{K}$ & JME-FS & iyi & & $\begin{array}{l}\text { NPA ile provokasyon (Rubik küp, Türkçe ve İngilizce } \\
\text { okuma, Yazarak hesaplama) }\end{array}$ \\
\hline $40 y, E$ & JME-FS & iyi & Tamirat işleri yapmak ${ }^{*}$ & $\begin{array}{l}\text { NPA ile provokasyon (Yazarak hesaplama, Mental } \\
\text { hesaplama, Türkçe ve İngilizce okuma, Konuşma, Rubik } \\
\text { küp, Kopyalama) }\end{array}$ \\
\hline $35 \mathrm{y}, \mathrm{K}$ & $\mathrm{AE}$ & iyi & & $\begin{array}{l}\text { IFS + NPA ile provokasyon (Türkçe okuma, Konuşma, } \\
\text { Mental hesaplama) }\end{array}$ \\
\hline $27 y, k$ & $\mathrm{AE}$ & iyi & $\begin{array}{l}\text { Uzun süreli sıkıntılı } \\
\text { konuşma* }\end{array}$ & $\begin{array}{l}\text { HV + NPA ile provokasyon } \\
\text { (Yazma, Konuşma, Yazarak hesaplama, Mental hesaplama) }\end{array}$ \\
\hline $32 \mathrm{y}, \mathrm{K}$ & $\mathrm{AE}$ & kötü & $\begin{array}{l}\text { Mental aktivasyon, } \\
\text { konsantrasyon }^{*}\end{array}$ & $\begin{array}{l}\text { IFS + NPA ile provokasyon } \\
\text { (Mental hesaplama, Dikkat testi, Yazma) }\end{array}$ \\
\hline $55 \mathrm{y}, \mathrm{E}$ & NBFE & kötü & & $\begin{array}{l}\text { HV ile provokasyon } \\
\text { NPA ile inhibisyon (Yazarak hesaplama, İngilizce okuma, } \\
\text { Yazma, Konuşma, Mental hesaplama) }\end{array}$ \\
\hline $21 \mathrm{y}, \mathrm{E}$ & NBFE & kötü & & $\begin{array}{l}\text { HV + IFS + NPA ile provokasyon } \\
\text { Türkçe okuma, Yazarak hesaplama }\end{array}$ \\
\hline $38 \mathrm{y}, \mathrm{K}$ & NBFE & kötü & & $\begin{array}{l}\text { NPA ile provokasyon (Kopyalama, İngilizce ve Türkçe } \\
\text { okuma) }\end{array}$ \\
\hline $32 \mathrm{y}, \mathrm{K}$ & NBFE & kötü & & NPA ile provokasyon (Dikkat testi) \\
\hline $31 \mathrm{y}, \mathrm{E}$ & NBFE & kötü & & NPA ile provokasyon (Rubik küp, Türkçe okuma) \\
\hline $48 y, E$ & NBFE & kötü & & NPA ile provokasyon (Konuşma) \\
\hline
\end{tabular}

JME-FS: Fotosensitif jüvenil miyoklonik epilepsi; JME-NFS: Fotosensitif olmayan jüvenil miyoklonik epilepsi; NBFE: Nedeni bilinmeyen fokal epilepsi; NPA: Nöropsikolojik aktivasyon; NPA-EEG: Nöropsikolojik aktivasyonlu elektroensefalografi; HV: Hiperventilasyon; IFS: İntermittant fotik stimülasyon. *Bold belirtilenler anket cevabı ile NPA-EEG sonucu arasındaki uyumu göstermektedir.

Sadece her iki konvansiyonel aktivasyon yönteminin birden (HV ve IFS) aynı kişide ED'leri provoke ettiği hasta sayısı 2 (1 $J M E, 1 \mathrm{AE}$ ) (\%3) idi. IFS ve NPA'nın aynı kişide ED'leri provoke ettiği kişi sayısı 6 (3 JME, 2 AE, 1 FE) iken; HV ve NPA'nın aynı kişide ED'leri provoke ettiği kişi sayısı 4 (1 $\mathrm{AE}, 1 \mathrm{FE}, 2$ JME) idi. Aynı hastada HV ve IFS sırasında ED provokasyonu saptanmayanların oranı \%62.1 ( $\mathrm{n}=41 ; 20 \mathrm{JME}, 10 \mathrm{AE}, 11 \mathrm{FE})$ idi. Şekil 1'de, NPA ve konvansiyonel yöntemler ile ED'lerin provokasyonu görülen hasta sayıları sunulmuştur.

Praksi için; Rubik küp, yazma, yazarak hesaplama, kopyalama sırasında ED'lerde provokasyon görülen hastalar da dikkate alınmış olup; JME grubunda beş hastada, AE grubunda iki hastada, NBFE grubunda ise üç hastada praksi ile provokasyon izlenmiştir. Ayrıca, JME ve AE gruplarındaki dört has- tada ankette bildirdikleri tetikleyicilerle uyumlu olarak NPA sırasında ED'lerinde provokasyon olduğu izlenmiştir (Tablo 5). JME'de daha sık olmak üzere $(n=5)$ tüm hasta grubunda kognitif testler arasında en sık tetikleyici praksi (\%15) idi, bunu okuma (\%10.6), mental hesaplama (\%9) ve dikkat testi (\%3) takip etmiştir. Şekil 2 ve 3'te sırasıyla praksi ve okuma ile provokasyon izlenen hastaların EEG örnekleri izlenmektedir. Tablo 5'te ise NPA ile EEG'de provokasyon/inhibisyon görülen hastaların özellikleri sunulmuştur.

\section{Tartışma}

Bu çalışmada, NPA ile ED'lerin provokasyon oranı konvansiyonel yöntemlerle (HV/IFS) izlenen orana oldukça yakın bulundu. Bununla beraber, hastaların \%11'inde konvansiyonel 
yöntemlerin negatif kaldığı ve sadece NPA yöntemleri ile ED provokasyonu olduğu saptandı ve bu olguların yarısında da bazalde hiç ED yokken sadece NPA ile ED'ler tetiklendi. Ayrıca anket sırasında, bildirilenle uyumlu olarak, dört hastanın ED'lerinin ilişkili tetikleyiciler ile provoke olduğu izlendi; dolayısıyla bazı olgularda, NPA tanıyı doğrulama anlamında da yarar sağlayabilecek bir yöntem olarak öne çıktı. Çalışmamız, hastaların nöbet tetikleyicilerinin iyi sorgulanarak EEG kayıtları sırasında spesifik tetikleyicilere yönelik NPA yöntemlerinin planlanmasının ve özellikle EEG'lerinde standart aktivasyon yöntemleri ile ED görülmeyen hastalarda NPA'nın provokasyon yöntemi olarak uygulanmasının tanı koymada ek katkı sağladığını göstermesi açısından önemlidir.

Nöropsikolojik aktivasyon yöntemleriyle ED'lerin inhibisyon ve provokasyon oranları açısından ilginç sonuçları olan öncül araştırmalardan biri Matsuoka ve ark.nın ${ }^{[10]}$ oldukça geniş bir seriden oluşan ( $n=480$ ) epilepsi hastalarında yaptıkları çalışmadır. NPA'lı EEG'nin provokatif etkisi olduğunu, bu provokatif etkinin izlendiği hastaların neredeyse tamamının GJE'lilerden oluştuğunu, FE'lilerde ise oldukça seyrek olarak provokatif etki gözlediklerini bildirmişlerdir. Öte yandan hastaların \%63.9'unda NPA'nın inhibitör etkisinden bahsetmişlerdir. Bu çalışmanın analiz yöntemine EEG'deki deşarjların spontan dalgalanmalarının dikkate alınmadığına dair Beniczky ve ark.'dan ${ }^{[11]}$ ciddi bir eleştiri gelmiştir. ${ }^{[10]}$

Jüvenil miyoklonik epilepsililerde bulduğumuz ED'lerin provokasyon oranı, Beniczky ve ark.nın ${ }^{[1]} \mathrm{JME}^{\prime} l i \quad 60$ hasta ile yaptıkları benzer aktivasyon ve istatistiksel analiz yönteminin kullanıldığı çalışmalarında saptadıkları oranla (\%18) benzerdi. Ancak inhibitör etkiler açısından oldukça farklı sonuçlar elde ettik. Beniczky ve ark. ${ }^{[1]}$ NPA yöntemleri ile (\%29) ED'lerde inhibisyon gördüklerini bildirmişlerdir. Çalışmamızda ise bu oran çok daha düşüktü. Aradaki bu fark, kayıtlarını uyku deprivasyonlu hastalarda sabah saatlerinde ve daha uzun süreli olarak yapmış olmaları bazal EEG kaydında daha fazla sayıda hastada ED görülmesine, dolayısıyla da daha fazla hastada inhibisyonu değerlendirmiş olmalarından kaynaklanmış olabilir. Çalışmamız ise, uyku deprivasyonunun EEG üzerindeki etkisini elimine etmek için hastaların uykularını iyi almış olmalarına dikkat edilerek öğlen saatlerinde kayıt yapılacak şekilde planlandı.

Praksi; görsel motor koordinasyon ve düşünme gerektiren motor bir hareket planlaması ile ilişkili mekânsal işlevleri içermekte olup; literatürde praksinin sıklıkla JME'lilerde miyoklonileri tetiklediğinden bahsedilmektedir. ${ }^{[10-12,16]}$ JME grubumuzda 5 (\%14.7) hastada praksi ile ED'lerin provoke olduğunu saptadık. Günlük hayatta daha çok uykusuzlukla sabah miyoklonilerinden yakınan bir hastada praksi sonrası absans nöbeti gelişmesini oldukça ilginç bir bulgu olarak değerlendirdik. JME hastalarında praksi ile tetiklenme oranları bazı araştırmalarda çok daha yüksek bulunmuştur. ${ }^{[16,17]} \mathrm{Ay}$ rıca, Mayer ve ark., ${ }^{[16]}$ okuma sırasında JME'lilerin \%36'sında okuma ve konuşma sırasında ED provokasyonu, \%24'ünde de okuma sırasında perioral refleks miyokloni kaydettiklerini bildirmişlerdir. Bizim çalışmamızda ise JME'lilerin \%9'unda, tüm grubun ise \%12'sinde okuma ile (Ingilizce veya Türkçe) ED'lerde provokasyon izlendi. Diğer yandan JME ve FE gruplarında birer hastada okuma ile ED'lerde inhibisyon olduğu görüldü. Okuma ile bu kadar yüksek oranda tetiklenme görmelerinin başlıca nedeninin, öncesinde anket yaparak praksi, okuma, ışık gibi tetikleyici faktörleri olduğunu söyleyen hastaların arasından seçerek EEG kaydı yapmış olduklarını düşünmekteyiz. Buna ek olarak, test sürelerinin (minimum 15 dakika) ve dolayısıyla tüm kayıt süresinin (>3 saat) bizim çalışmamıza göre çok daha uzun tutulmuş olmasının, etnik nedenlerin ve de analiz yöntemlerinde spontan dalgalanmaları dikkate almamalarının ED'lerin provokasyonu açısından fark yaratmış olabileceği kanısındayız. Literatürde daha uzun süreli aktivasyonların, özellikle okuma ile ED'leri ortaya çıkarması açısından daha provokatif olduğu vurgulanmıştır, ancak çalışmamızda kısa sürede pratik şekilde uygulanabilecek kognitif testlerin etkisini araştırmak hedeflenmiştir.

Fokal epilepsi grubunda NPA ile provokasyon oranı ise beklenenden yüksek (\%31.2) saptandı. ${ }^{[10,18]}$ FE'lilerin dahil edildiği az sayıdaki NPA'lı EEG çalışmasında, FE grubunda JME ile karşılaştırıldığında oldukça düşük oranda ED'lerde provokasyon görüldüğü bildirilmiştir. ${ }^{[10,16]} \mathrm{FE}^{\prime} l i$ hastalarda EEG'de ED saptanma olasılığının daha düşük olduğu ve ayrıca uzun süreli video-EEG monitörizasyonu yapılan hastalara NPA uygulamayı planladığımız için FE'liler arasından dirençli olan olguları araştırmaya dahil ettik. Çalışmamızda GJE'lilerle kıyaslandığında FE'lilerde daha yüksek oranda provokasyon görülmüş olması, bu gruba aldığımız hastaların tümünün dirençli epilepsilerinin olmasına bağlı olabilir. Diğer yandan FE'si olan hastalarda birçok refleks uyaranın (dokunma, müzik, okuma, yemek gibi) refleks nöbete neden olduğunun bildirilmiş olması bulgularımızı desteklemektedir. ${ }^{[19]}$ Sonuç olarak, NPA uygulanan az sayıda çalışma olduğu için, FE için daha fazla hasta sayılı ve standardize çalışmalara ihtiyaç olduğunu düşünmekteyiz.

Absans epilepside de NPA yöntemleri az araştırılmış bir konudur. JME'ye benzer oranda AE'lilerin \%18'inde ED'lerin NPA ile provoke olduğunu saptadık. Matsuoka ve ark., ${ }^{[10]}$ JME'de hastaların \%46.7'sinde, JAE'de \%15.8'inde ve ÇÇAE'de \%7.1'inde praksinin ED'lere provokatif etkisini bildirmişlerdir. Daha önce yapılmış başka çalışmalarda da praksinin JME'liler arasında absanslılara göre daha sık oldu- 
ğu bildirilmiştir. ${ }^{[20,21]}$ Çalışmamızda ise praksi ile tetiklenmenin, JME (\%14.7) ve AE'de (\%12.5) benzer oranlarda olduğu izlendi. Son zamanlarda yapılmış olan GJE'lilerde praksi ile kognitif performans arasındaki ilişkiyi araştıran araştırmanın sonuçları ise $A E^{\prime}$ de praksi ile provokasyon açısından oldukça dikkat çekicidir. ${ }^{[22]}$ Uygulanan testlerin sürelerinin uzun olmasının provokasyon oranlarının artmasında önemli bir etken olabileceğini düşünmekle beraber, bu çalışmada da spontan dalgalanmaları elimine etmek için $\% 95 \mathrm{Cl}$ değerinin dikkate alınmamış olmasının yine bu yüksek provokasyon oranlarında etkisi olabileceği kanısındayız.

Mental hesaplamanın EEG üzerindeki etkisinin daha çok inhibisyon yönünde olduğu vurgulanmış olup bunun artmış dikkate bağlı olabileceği söylenmiştir. ${ }^{[10,11]}$ Biz de hem mental hesaplamayı hem de karmaşık bir sırada olan harfleri bulmaya yönelik olan dikkat testini uyguladık. Ancak hastaların ikisinde mental hesaplama ile, birinde de dikkat testi ile olmak üzere sadece iki hastada NPA ile inhibisyon izledik. Diğer yandan hastaların $\% 9$ 'unda mental hesaplama ile, \%3'ünde ise dikkat testi ile provokatif etki izledik. Dikkat testlerini daha uzun süreli uygulamak belki de inhibitör etkilerin daha yüksek oranda ortaya çıkmasına neden olabilirdi.

Konvansiyonel aktivasyon yöntemlerini gruplar arasında karşılaştırdığımızda, HV ile ED'lerin provokasyon oranları AE'de (\%31.25) ve JME'de (\%23.5) literatürle uyumlu olarak bulunurken, dirençli FE (\%18.75) grubunda ise daha yüksek oranda saptand. ${ }^{[2,2,24]}$ Bunun başlıca nedeni GJE grubundakilerin çoğunun tedaviye iyi yanıtlı iken, FE grubundakilerin tedaviye dirençli olması olabilir. Bununla beraber, FE'de HV'nin ED'leri tetiklemesi ile ilgili farklı sonuçları olan çalışmalar da bulunmaktadır. Bir video-EEG çalışmasında dirençli FE'li hastaların başlıca temporal lob epilepsisi ve MTLE olmak üzere neredeyse $1 / 3$ 'ünde nöbetleri aktive ettiği izlenmişken; geniş serili başka bir çalışmada FE grubunda HV'nin sadece iki hastada nöbet aktivitesini tetiklediği, interiktal epileptiform deşarjları (ED) indükleme oranlarının da oldukça düşük (GJE'de \%12.2, FE'de \%3.4) olduğu bildirilmiştir. ${ }^{[24,25]}$ Bir diğer konvansiyonel yöntem IFS ile ise çalışmamızda yer alan FE'liler arasında sadece bir hastada ED'ler provoke olmuşken, literatürde bildirilenlere yakın oranda GJE'lilerin \%25'inde IFS ile ED'lerin provokasyonu izlenmiştir. ${ }^{[26]}$ Daha önceki bazı yayınlarda IFS ile FE'lerde ED'lerin inhibe olduğu vurgulanmıştır. ${ }^{[2]}$ Her ne kadar biz IFS ile inhibisyon izlememiş olsak da FE'lilerde IFS ile tetiklenme oranının GJE grubuna göre anlamlı olarak düşük olduğunu ortaya koyduk. Guaranha ve ark.nın ${ }^{[12]} J M E^{\prime}$ lilerle yaptıkları çalışmada NPA'lı EEG ile hastaların \%38.2'sinde provokatif, \%35.5'inde ise hem provokatif hem de inhibitör etki bildirilirken; HV ile \%38.6'sında, IFS ile de \%29.7'sinde provokatif izlendiği bildirilmiştir.
Nöropsikolojik aktivasyonlu EEG öncesinde yapılan ankette düşünme ve konsantrasyon ile nöbetlerinin tetiklediğini belirten bir iki hastamızda mental hesaplama ile; uzun süreli sıkıntılı konuşmanın tetikleyici olduğunu söyleyen bir hastamızda konuşma ile; tamirat işleri yaparken miyokloni tarif eden hastamızın praksi testleri ile EEG'lerinde ED açısından da provokasyon görülmesi hastalarda tetikleyicilerin sorgulanmasının önemini kanıtlar niteliktedir.

Çalışmamızda NPA ile ED'lerin provokasyonunda öne çıkan özellikler arasında provokasyon izlenen hastaların çoğunun (\%71.4) birden fazla kognitif uyaran sırasında ED'lerinin artmış olduğu, ayrıca benzer bir özelliğin inhibisyon izlenen her iki hastada da izlenmesiydi. Praksinin JME'de daha sık olmak üzere tüm hasta grubunda kognitif testler arasında en sık tetikleyici (\%15) olduğu, bunu okuma (\%10.6) ve mental hesaplamanın (\%9) takip ettiği saptandı. Yine kognitif uyaranlar sonrası, postaktivasyon dönemlerinde görülen uzamış etkilerin varlığı da dikkat çekiciydi.

Limitasyonlar- Hastaların hepsinin etik nedenlerle antiepileptik kullanıyor olmaları, hasta sayısının görece azlığı, nöbet sıklıklarının ve sürelerinin farklı olması çalısmamızın kısıtlayıcı özelliklerini oluşturmaktadır. Her ne kadar hastalara rutin olarak göz açma ve kapama yaptırmış olsak da diken/ keskin aktivitesi sayarken göz açma ve kapama periyotlarına dikkat edilerek sayım yapılması çalışmanın dizaynı nedeni ile mümkün olmadı. Göz açma-kapama aktivasyonunu istatistiksel olarak değerlendiremedik.

Sonuç- Sonuç olarak; FE'de ve AE'de az araştıııımış bir konu olan refleks özellikleri görece daha iyi araştıııımış olan JME ile karşılaştırdık ve bu her iki grupta da JME ile benzer oranlarda NPA yöntemleri ile ED'lerde provokasyon olduğunu ortaya koyduk. Çalışmamız, JME dışındaki sendromlarda da refleks özelliklerin varlığına dikkat çekmesi ve NPA'nın etkisi açısından önemlidir. Hastaların provoke olduğu yöntemlerin objektif olarak belirlenmesi klinik planda nöbetleri azaltıcı bireysel korunma stratejilerinin bulunmasına yardım edebilir. Öte yandan hem çalışmamızda hem de literatürde aynı sendromda hatta aynı hastada belli bir uyaranın hem inhibitör hem de provokatif etkisi olabilmesi de ilişkili nöronal ağların farklı durumlarda (stres, hormonal, diürnal vb. değişkenler) verdikleri farklı yanıtlara işaret ettiğinden üzerinde durulması ve araştırı ması gereken bir boyutu düşündürmektedir.

Teşekkür- Bu çalışma, İstanbul Üniversitesi Bilimsel Araştırma Projeleri Birimi tarafından desteklenmiştir (Proje No: TYL-25538).

Etik Komite Onayı- Etik kurul onayı alındı. 
Hakem Değerlendirmesi- Dış bağımsız.

\section{Çıkar Çatışması- Yoktur.}

Yazarlık Katkıları- Konsept: B.B.; Dizayn: E.U.Ö., B.B.; Kontrol: E.U.Ö., D.A., N.G.Ş., A.K., N.B., B.B.; Veri Toplama veya İşleme: E.U.Ö., D.A., N.G.Ş., N.B.; Analiz ve Yorumlama: E.U.Ö., D.A., N.G.Ş., A.K., N.B.; Literatür Arama: E.U.Ö., B.B.; Yazan: E.U.Ö., B.B.

\section{Kaynaklar}

1. Engel J Jr; International League Against Epilepsy (ILAE). A proposed diagnostic scheme for people with epileptic seizures and with epilepsy: report of the ILAE Task Force on Classification and Terminology. Epilepsia 2001;42(6):796-803. [CrossRef]

2. Xue LY, Ritaccio AL. Reflex seizures and reflex epilepsy. Am J Electroneurodiagnostic Technol 2006;46(1):39-48. [CrossRef]

3. Kasteleijn-Nolst Trenité $D$, Rubboli G, Hirsch E, Martins da Silva A, Seri S, Wilkins A, et al. Methodology of photic stimulation revisited: updated European algorithm for visual stimulation in the EEG laboratory. Epilepsia 2012;53(1):16-24. [CrossRef]

4. Irmen F, Wehner T, Lemieux L. Do reflex seizures and spontaneous seizures form a continuum? Triggering factors and possible common mechanisms. Seizure 2015;25:72-9. [CrossRef]

5. Ferlisi M, Shorvon S. Seizure precipitants (triggering factors) in patients with epilepsy. Epilepsy Behav 2014;33:101-5.

6. Lunardi MDS, Sukys-Claudino L, Guarnieri R, Walz R, Lin K. Seizure precipitants and inhibiting factors in mesial temporal lobe epilepsy. J Neurol Sci 2011;308(1-2):21-4. [CrossRef]

7. Italiano D, Ferlazzo E, Gasparini S, Spina E, Mondello S, Labate $A$, et al. Generalized versus partial reflex seizures: a review. Seizure 2014;23(7):512-20. [CrossRef]

8. Walker MC, White HS, Sander JWAS. Disease modification in partial epilepsy. Brain 2002;125(9):1937-50. [CrossRef]

9. Wolf $P$, Beniczky $S$. Understanding ictogenesis in generalized epilepsies. Expert Rev Neurother. 2014 Jul;14(7):787-98.

10. Matsuoka H, Takahashi T, Sasaki M, Matsumoto K, Yoshida S, Numachi $Y$, et al. Neuropsychological EEG activation in patients with epilepsy. Brain 2000;123(2):318-30. [CrossRef]

11. Beniczky S, Guaranha MS, Conradsen I, Singh MB, Rutar V, Lorber $B$, et al. Modulation of epileptiform EEG discharges in juvenile myoclonic epilepsy: an investigation of reflex epileptic traits. Epilepsia 2012;53(5):832-9. [CrossRef]

12. Guaranha MS, da Silva Sousa P, de Araújo-Filho GM, Lin K, Guilhoto LM, Caboclo LO, et al. Provocative and inhibitory effects of a video-EEG neuropsychologic protocol in juvenile myoclonic epilepsy. Epilepsia 2009;50(11):2446-55. [CrossRef]
13. Scheffer IE, Berkovic S, Capovilla G, Connolly MB, French J, Guilhoto L, et al. ILAE classification of the epilepsies: Position paper of the ILAE Commission for Classification and Terminology. Epilepsia 2017;58(4):512-21. [CrossRef]

14. Kwan P, Arzimanoglou A, Berg AT, Brodie MJ, Allen Hauser W, Mathern $G$, et al. Definition of drug resistant epilepsy: consensus proposal by the ad hoc Task Force of the ILAE Commission on Therapeutic Strategies. Epilepsia 2010;51(6):1069-77.

15. Maulsby RL. Some guidelines for assessment of spikes and sharp waves in EEG tracings. Am J EEG Technol 1971;11(1):3-16.

16. Mayer TA, Schroeder F, May TW, Wolf PT. Perioral reflex myoclonias: a controlled study in patients with JME and focal epilepsies. Epilepsia 2006;47(6):1059-67. [CrossRef]

17. Karachristianou S, Bostantjopoulou S, Katsarou Z, Kazis A. Neuropsychological EEG activation in patients with juvenile myoclonic epilepsy. Funct Neurol 2004;19(3):185-9.

18. Wolf $\mathrm{P}$, Goosses R. Relation of photosensitivity to epileptic syndromes. J Neurol Neurosurg Psychiatry 1986;49(12):1386-91.

19. Mameniškienè $R$, Wolf $P$. Precipitation and inhibition of seizures in focal epilepsies. Expert Rev Neurother 2018;18(4):275-87.

20. InoueY. Epilepsy with praxis-induced epilepsy. In: Wolf $\mathrm{P}$, editor. Epileptic Seizures and Syndromes. London: John Libbey; 1994. p. 81-92.

21. Yacubian EM, Wolf P. Praxis induction. Definition, relation to epilepsy syndromes, nosological and prognostic significance. A focused review. Seizure 2014;23(4):247-51. [CrossRef]

22. Abarrategui B, Parejo-Carbonell B, García García ME, Gil-Nagel A, García-Morales I. Praxis induction and its relationship with cognition in genetic generalized epilepsy. Epilepsy Behav 2020;102:106638.

23. Baldin E, Hauser WA, Buchhalter JR, Hesdorffer DC, Ottman R. Utility of EEG Activation Procedures in Epilepsy: A Population-Based Study. J Clin Neurophysiol 2017;34(6):512-9.

24. Holmes MD, Quiring J, Tucker DM. Evidence that juvenile myoclonic epilepsy is a disorder of frontotemporal corticothalamic networks. Neuroimage 2010;49(1):80-93. [CrossRef]

25. Guaranha MS, Garzon E, Buchpiguel CA, Tazima S, Yacubian EM, Sakamoto AC. Hyperventilation revisited: physiological effects and efficacy on focal seizure activation in the era of video-EEG monitoring. Epilepsia 2005;46(1):69-75. [CrossRef]

26. Poleon S, Szaflarski JP. Photosensitivity in generalized epilepsies. Epilepsy Behav 2017;68:225-33. [CrossRef]

27. Lunardi MS, Lin K, Mameniškienè R, Beniczky S, Bogacz A, Braga $P$, et al. Olfactory stimulation induces delayed responses in epilepsy. Epilepsy and Behav 2016;61:90-6. [CrossRef] 